\title{
CRYOPRESERVATION OF PLANT GENETIC RESOURCES: CONVENTIONAL AND NEW METHODS
}

\section{Toshikazu Matsumoto}

Faculty of Life and Environmental Science, Shimane University, Matsue 690-8504

\begin{abstract}
Plant genetic resources (PGR) are important for agriculture and are mainly conserved in seed and field genebanks. Cryopreservation is an in vitro conservation method, which has become an important tool for the long-term storage of PGR. Within this method, the techniques of vitrification and encapsulation/dehydration are commonly used worldwide. Recently, new cryogenic methods using cryo-plates (the V cryo-plate and D cryo-plate) have been developed. The cryo-plate methods have advantages, such as ease of handling during the procedure and high regrowth rates after cryopreservation. It is important to research genetic stability in long-term tissue-cultured plants and cryopreserved plants for successful conservation of plant germplasm. The present paper reviews current cryopreservation techniques. Thus far, studies have reported no or small differences between cryopreserved and non-cryopreserved samples under optimized conditions according to various morphological, biochemical and molecular analyses (e.g., RAPD-PCR, AFLP, and MSAP).
\end{abstract}

Keywords: cryo-plate, cryopreservation, genetic stability, shoot tips, vitrification

\section{Introduction}

Plant genetic resources (PGR) include all crops and some crop wild relatives because of their valuable traits. PGR are highly important for food security and agro-biodiversity because they can be used to breed new or more productive crops that are resistant to biological and environmental stresses (Kaviani, 2011). The present paper reviews the current techniques for cryopreservation, which has become a crucial tool for long-term storage of plant germplasm as it requires minimal space and maintenance and preserves the genetic stability of regenerated plants. Cryopreservation is a method of storing plant materials at ultra-low temperatures, for example, that of liquid nitrogen (LN). All the metabolic activities of cells cease at such temperatures and no genetic changes occur during storage (Engelmann, 2004). Thus, this method has become a very important tool for the long-term storage of germplasm; furthermore, new experimental materials have been developed for cryopreservation with unique attributes that require minimal space and maintenance and do not cause genetic alterations (Sakai, 1995). Cryopreservation techniques are now used for plant germplasm storage at many institutes around the world (Niino, 2006). The most popular cryogenic procedures are vitrification (Sakai et al., 1990) and encapsulation/dehydration (Fabre and Dereuddre,
1990). Vitrification-based cryopreservation methods have been combined with other elements to develop new techniques, such as encapsulation/vitrification (Matsumoto et al., 1995a) and droplet vitrification (Schafer-Menuhr et al., 1997; Keller and Dreiling, 2002; Kim et al., 2009). Recently, cryopreservation protocols using an aluminum cryo-plate have also been reported (Sekizawa et al., 2011; Yamamoto et al., 2011, 2012abc; Niino et al., 2013). However, scientists have focused their efforts towards preventing potential genetic changes in cryopreserved and regenerated plant tissues. Thus far, these studies have shown no or small differences between cryopreserved and non-cryopreserved samples under optimized conditions (Harding and Staines, 2001; Martin and GonzalezBenito, 2005; Urbanova et al., 2006; Peredo et al., 2008; Castillo et al., 2010; Matsumoto et al., 2013; Maki et al., 2015).

\section{The principle of cryopreservation}

For successful cryopreservation, it is essential to avoid the lethal intracellular freezing that occurs during rapid cooling in LN (Sakai and Yoshida, 1967; Sakai, 1995). Thus, in any cryogenic procedure, the cells and shoot tips must be sufficiently dehydrated to avoid freezing and to allow vitrification upon rapid cooling in LN. The development of a simple and reliable method for cryopreservation 
would allow much more widespread use of cryopreserved cultured cells, shoot tips and somatic embryos (Sakai, 1997).

\section{The conventional cryogenic methods}

Plant cryopreservation techniques have been developed over more than 40 years (Reed, 2008). The classical cryopreservation methods (slow freezing and simple freezing) were developed in the 1970s to 1980s (Kaviani, 2011). In the slow freezing method, samples (shoot tips, embryo and cells) are packed in straw or a cryotube and treated with cryoprotectants (DMSO, glycerol, ethylene glycol and sucrose), inoculated on ice at $-7{ }^{\circ} \mathrm{C}$ and frozen at $0.3-0.5{ }^{\circ} \mathrm{C} / \mathrm{min}$ to $-40{ }^{\circ} \mathrm{C}$ using a programmable freezer for dehydration, and then immersed in LN (Kumu et al., 1983). In the simple freezing method, samples are packed in straw or a cryotube, treated with cryoprotectants at $25{ }^{\circ} \mathrm{C}$, frozen at $-30{ }^{\circ} \mathrm{C}$ for dehydration, and then immersed in LN (Withers et al., 1980).

Currently, the most popular cryogenic procedures are vitrification (Sakai et al., 1990) and encapsulation/dehydration (Fabre and Dereuddre, 1990). The difference between the two methods is the method of dehydration. In vitrification, cells are dehydrated by treatment in a highly concentrated solution such as PVS2 solution (Sakai et al., 1990). In encapsulation/dehydration, cells are dehydrated by air-drying; then, dehydrated cells can be vitrified by rapid cooling (immersion into $\mathrm{LN}$ ) and conserved safely for a long time. Since these methods were developed, the optimal procedures for preserving many kinds of plants, including tropical species, have been established (Sakai, 2008). Overall, the vitrification method has advantages over the encapsulation/ dehydration method, such as a higher rate of regrowth after recovery and a shorter treatment time.

\subsection{Vitrification}

The vitrification method was developed by Sakai et al. (1990), and has been applied to many kinds of plants, including tropical and subtropical species. This method requires a highly concentrated solution, which sufficiently dehydrates tissues without causing injury, enabling them to form a stable glass along with the surrounding highly concentrated solution when plunged into LN. In the vitrification method, cells or shoot tips must be sufficiently dehydrated with highly concentrated vitrification solution at $0{ }^{\circ} \mathrm{C}$ or $25{ }^{\circ} \mathrm{C}$ without undergoing any injuries prior to direct transfer to LN. A less toxic vitrification solution, designated PVS2 (30\% (w/v) glycerol, $15 \%(\mathrm{w} / \mathrm{v})$ ethylene glycol and $15 \%(\mathrm{w} / \mathrm{v})$ DMSO in culture medium containing $0.4 \mathrm{M}$ sucrose at $\mathrm{pH} 5.8$ ), was first developed to preserve the nucellar cells of navel orange. This solution can be easily supercooled below $-70{ }^{\circ} \mathrm{C}$ when it is cooled rapidly and solidified into a metastable glass at approximately $-115{ }^{\circ} \mathrm{C}$. On subsequent slow warming, the vitrified PVS2 shows a glass transition at $-115^{\circ} \mathrm{C}$, followed by exothermic devitrification (crystallization) and endothermic melting (Matsumoto and Niino, 2014).
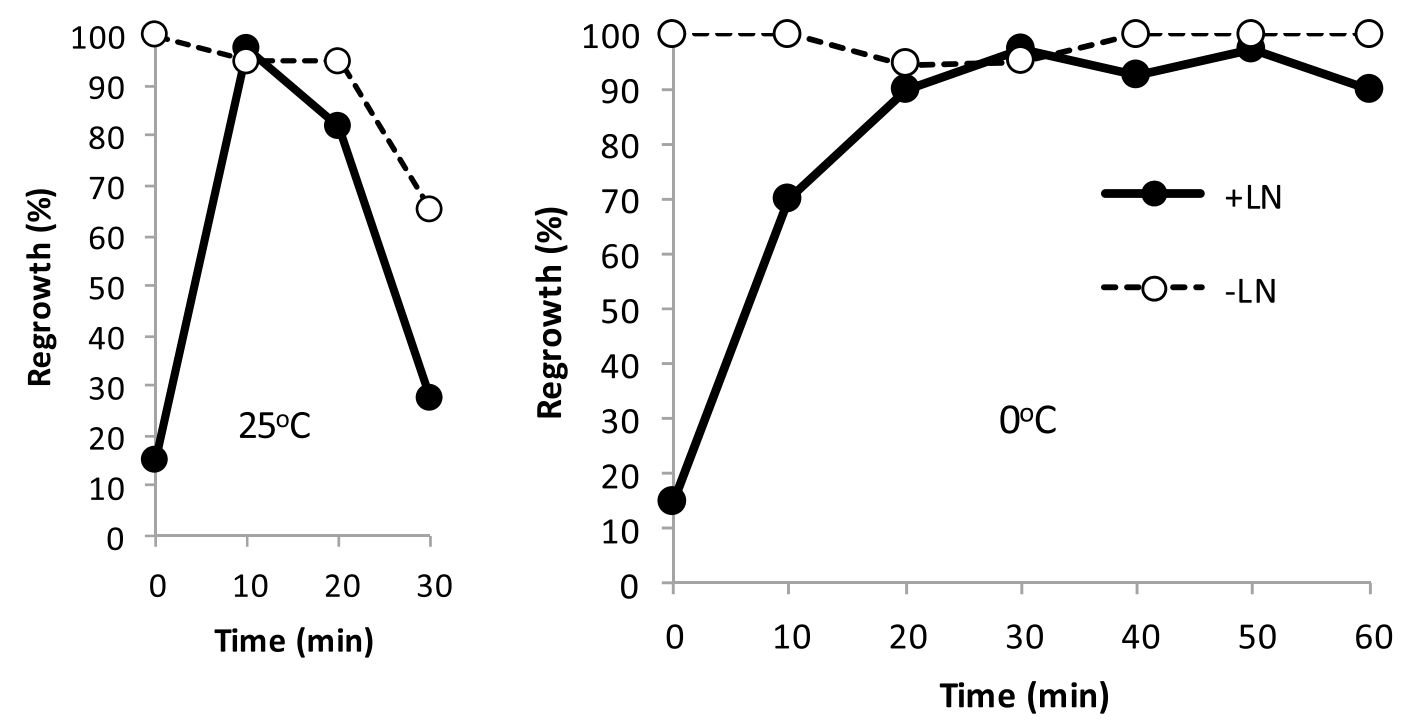

Fig.1. Effect of exposure time to PVS2 at 25 or $0{ }^{\circ} \mathrm{C}$ on recovery growth from wasabi shoot tips cooled to $-196{ }^{\circ} \mathrm{C}$ by vitrification. Shoot tips (1 mm size) were precultured with $0.3 \mathrm{M}$ sucrose for $1 \mathrm{~d}$ and then treated with a mixture of $2 \mathrm{M}$ glycerol plus $0.4 \mathrm{M}$ sucrose (LS solution) for $20 \mathrm{~min}$ at $25^{\circ} \mathrm{C}$. These shoot tips were treated with PVS2 for different lengths of time prior to immersion in LN. (Matsumoto et al., 1994). 
Please cite this article as

Matsumoto, Reviews in Agricultural Science, 5:13-20, 2017

Doi: $10.7831 /$ ras 5.13



The shoot tips of many plants cannot be successfully cryopreserved using direct PVS2 dehydration because it damages cells or tissues owing to harmful effects from osmotic stress or chemical toxicity, which result in low or no regrowth after cryopreservation. The two osmo-protection treatments, sucrose preculture and LS treatment $(2 \mathrm{M}$ glycerol $+0.4 \mathrm{M}$ sucrose solution), are very effective for inducing osmo-tolerance and obtaining high rates of regrowth after cryopreservation. Using the two osmo-protection treatments, high rates of recovery growth after cryopreservation by vitrification have been obtained for many plant species. Exposure to PVS2 for various durations has resulted in variable rates of shoot formation. The highest level of recovery was obtained with wasabi shoot tips treated with PVS2 for 10 min at 25 ${ }^{\circ} \mathrm{C}$ or for $30-50 \mathrm{~min}$ at $0{ }^{\circ} \mathrm{C}$, respectively (Matsumoto et al., 1994). Wasabi shoot tips treated with PVS2 for up to $20 \mathrm{~min}$ at $25^{\circ} \mathrm{C}$ or for up to about $60 \mathrm{~min}$ at $0{ }^{\circ} \mathrm{C}$ without cooling into $\mathrm{LN}(-\mathrm{LN})$ retained high levels of recovery (about $90 \%$ ).

\subsection{Encapsulation/dehydration}

The encapsulation/dehydration method was first reported by Fabre and Dereuddre (1990). In this method, shoot tips or embryo are precultured with $0.3-0.6 \mathrm{M}$ sucrose medium for 1-3 days, then encapsulated into alginate beads and treated with highly concentrated sucrose solution (approx. $0.8 \mathrm{M}$ ) for $16 \mathrm{~h}$. These treatments induce dehydration tolerance in the samples. After the pretreatment, samples are dehydrated on silica gels or in a laminar flow cabinet to reach their optimal hydration levels. The sucrose molarity increases markedly during the drying process and reaches or exceeds the saturation point of the sucrose solution, resulting in glass transition during cooling to -196 oC (Dereuddre et al., 1991). This method eliminates the need for other cryoprotectants that have been implicated in inducing genetic changes after cryopreservation, such as DMSO and ethylene glycol. The encapsulation/dehydration method has been successfully applied to a wide range of plant species and cultivars. However, lower levels of initial and later recovery growth were observed compared with shoot tips cryopreserved by vitrification (Matsumoto et al., 1995a).

Encapsulation/dehydration is a very efficient cryopreservation technique that is simple and user-friendly and enables us to overcome the problems associated with the sensitivity of plant materials to PVS2 vitrification solution (Engelmann et al., 2008). The critical factors for obtaining high rates of plant regrowth after cryopreservation with this method are the desiccation duration and osmo-protection treatment of shoot tips. The recovery of dehydrated wasabi shoot tips at various water contents before and after cooling into LN are shown in Fig.2 (Matsumoto et al., 1995a). Shoot formation increased with decreasing water content and reached the highest rate (approx. $65 \%$ ) at $18-20 \%$ water contents.



Water content of beads (\%)

Fig.2. Recovery growth of wasabi shoot tips at various water contents cooled to $-196{ }^{\circ} \mathrm{C}$ by encapsulation/dehydration. Shoot tips (1 mm size) were precultured with $0.3 \mathrm{M}$ sucrose for $1 \mathrm{~d}$ and then treated with $0.8 \mathrm{M}$ sucrose solution for $16 \mathrm{~h}$ at $20^{\circ} \mathrm{C}$ before dehydration by silica gel. (Matsumoto et al., 1996). 
Please cite this article as Matsumoto, Reviews in Agricultural Science, 5:13-20, 2017 Doi: $10.7831 /$ ras5.13

Subsequently, the recovery decreased due to desiccation injury.

\subsection{Vitrification based methods}

The encapsulation/dehydration technique is easy to handle and simplifies the dehydration process, but it is laborious and timeconsuming compared with the vitrification method. In contrast, the vitrification method has relatively complicated procedures, careful handling is necessary, and it is difficult to process a large number of shoot tips at the same time. To overcome these problems, vitrification-based cryogenic methods have been combined with other elements to develop new techniques: encapsulation/ vitrification (Matsumoto et al., 1995a) and droplet vitrification (Schäfer-Menuhr et al., 1997; Keller and Dreiling, 2002).

In encapsulation/vitrification, shoot tips are encapsulated in alginate beads and then treated with the vitrification method (Matsumoto et al., 1995a). Thus, the materials are easy to handle and it is possible to treat a large number of shoot tips simultaneously. Furthermore, the encapsulation/vitrification method may be more suitable for small specimens, such as hairy roots as well as callus and suspension cultures. This method was applied to the shoot tips of lily (Matsumoto et al., 1995b), statice (Matsumoto et al., 1998), strawberry (Hirai et al., 1998) and shoot primordia of horseradish (Phunchindawan et al., 1997). The rate of recovery growth with encapsulation/vitrification was the same as that of vitrification and regrowth occurred much faster when encapsulated air-dried shoot tips of wasabi were preserved. Shoot formation of wasabi shoot tips cooled to $-196{ }^{\circ} \mathrm{C}$ was compared with three different cryogenic procedures. Vitrification and encapsulation/vitrification produced much higher levels of shoot formation than that of encapsulation/dehydration (Table 2). In addition, in the vitrified shoot tips with or without encapsulation, shoot formation and the shoot growth after reculture were faster than those of the encapsulated dried shoot tips. The time used for dehydration was greatly decreased in the encapsulation/ vitrification compared to that of encapsulation/dehydration.

Droplet-vitrification was developed by Kartha et al. (1982) modified by Leunufna and Keller (2003). In this method, shoot tips are treated with vitrification using PVS2 and then inserted individually in 5-10 $\mu 1$ droplets of PVS2, which are placed on a piece of aluminum foil, and then are immersed directly in LN. The main advantage of this technique is the possibility of achieving very high cooling/warming rates owing to the tiny volume of cryoprotective medium in which the explants are placed. This method has been applied to the shoot tips of potato (Keller and Dreiling, 2002), yam

Table 1: Effects of preculture and LS treatment on recovery of wasabi shoot tips cryopreserved by vitrification.

\begin{tabular}{cccc}
\hline Preculture & LS treatment & \multicolumn{2}{c}{ Recovery $(\%)$} \\
\hline- & - & $10.0 \pm 1.4$ \\
+ & + & $73.3 \pm$ & 2.4 \\
+ & - & $61.2 \pm$ & 2.7 \\
+ & + & $100.0 \pm$ & 0 \\
\hline
\end{tabular}

Precultured shoot tips were treated with $2 \mathrm{M}$ glycerol plus $0.4 \mathrm{M}$ sucrose for 20 $\min$ at $25^{\circ} \mathrm{C}$, and then dehydrated with PVS2 before cooling in LN. Recovery (\%): persent of shoot tips that produced normal shoots 21 days after reculture.

(Matsumoto et al., 1994, modified)

Table 2: Recovery, shoot length and time used for dehydration of wasabi shoot tips cooled to $-196^{\circ} \mathrm{C}$ by three different cryogenic protocols

\begin{tabular}{lccccccc}
\hline \multicolumn{1}{c}{ Cryogenic protocol } & \multicolumn{2}{c}{$\begin{array}{c}\text { Recovery } \\
(\% \pm \text { S.E. })\end{array}$} & $\begin{array}{c}\text { Shoot length } \\
(\mathrm{mm})\end{array}$ & $\begin{array}{c}\text { Time used for } \\
\text { dehydration }(\mathrm{min})\end{array}$ \\
\hline Vitrification $^{1}$ & 97.5 & \pm & 1.0 & $11 \pm$ & 4.0 & 10 at $25^{\circ} \mathrm{C}$ \\
Encapslation/dehydration $^{2}$ & 67.1 & \pm & 8.9 & $6 \pm$ & 3.6 & 420 at $25^{\circ} \mathrm{C}$ \\
Encapsulation/vitrification $^{1}$ & 96.7 & \pm & 2.9 & $12 \pm$ & 3.6 & 100 at $0{ }^{\circ} \mathrm{C}$ \\
\hline
\end{tabular}

${ }^{1}$ Precultured shoot tips were treated with $2 \mathrm{M}$ glycerol plus $0.4 \mathrm{M}$ sucrose for $20 \mathrm{~min}$ at $25^{\circ} \mathrm{C}$, and then dehydrated with PVS2 before cooling in LN. ${ }^{2}$ Precultured shoot tips were encapsulated with alginate gel beads, and then treated with $0.8 \mathrm{M}$ sucrose for $16 \mathrm{hr}$ at $20^{\circ} \mathrm{C}$ before dehydration and cooling into LN. Recovery (\%): percent of shoot tips that produced normal shoots 21 days after reculture.

(Matsumoto et al., 1995a, modified) 
(Leunufna and Keller, 2003), banana (Panis et al., 2005), sweet potato (Pennycook and Towill, 2001) and garlic (Kim et al., 2009).

\subsection{Cryo-plate methods}

Recently, new cryogenic procedures using cryo-plates (V cryo-plate and D cryo-plate) have been developed. The V cryo-plate method (Yamamoto et al., 2011) is based on PVS2vitrification dehydration of explants on a cryo-plate (Fig. 3) and the D cryo-plate method (Niino et al., 2013) is based on air dehydration. Precultured ( $0.3 \mathrm{M}$ sucrose) shoot tips are attached to small wells of a cryo-plate with alginate beads and treated with LS solution (2 M glycerol + 0.6-1 M sucrose) for 15-30 min, then dehydrated with PVS2 solution (V cryo-pate method) or in a laminar flow cabinet (D cryo-pate method) for a suitable duration. Then the cryoprotected and dehydrated shoot tips are immersed in LN directly. For regrowth, shoot tips attached to the cryo-plate are transferred to a $1 \mathrm{M}$ sucrose solution for rapid warming and unloading at $25^{\circ} \mathrm{C}$ for $15 \mathrm{~min}$, and plated on a culture medium.

High rates of regrowth are expected using the cryo-plate methods due to the very high cooling and warming rates. The $\mathrm{V}$ cryo-plate method has been reported for strawberry (Yamamoto et al., 2012b), Dalmatian chrysanthemum (Yamamoto et al., 2011b), mint (Yamamoto et al., 2012a), mulberry (Yamamoto et al., 2012c), carnation (Sekizawa et al., 2011), mat rush (Niino et al., 2014), blueberry (Matsumoto et al., 2014a), Perilla (Matsumoto et al., 2014b) and sugarcane (Rafique et al., 2015) shoot tips/buds. More recently, Niino et al. (2013) reported on the D cryo-plate method. In that study, shoot tips adhered continuously to the cryo-plates throughout the whole procedure, enabling cryopreservation to be carried out efficiently. These techniques have two main advantages: they are user-friendly because samples held in aluminum plates are easy to handle, and they have a high rate of regrowth owing to the very high cooling and warming rates (Niino et al., 2013). In the D cryo-plate method, large specimens consisting of buds covered with base sheaths and basal stems can be used as the preservation materials, making the method practical and efficient (Niino et al.
2014). The key to successful cryopreservation with the D cryo-plate technique is to induce osmoprotection of shoot tips by preculturing with sucrose and loading solution treatment and determining the optimal dehydration time. This method has been reported for mat rush (Niino et al., 2013; 2014), date palm (Salma et al., 2014), persimmon (Matsumoto et al., 2015), blueberry (Dhungana et al., 2015) and potato (Yamamoto et al., 2015). Niino et al. (2013) reported that the advantages of the $\mathrm{D}$ cryo-plate technique are that it can be applied for larger specimens and that it is less laborious than other cryopreservation methods. Furthermore, the D cryoplate technique overcomes the problems associated with sensitivity to PVS2, such as insufficient or excessive dehydration as well as damage to or loss of material during excision and manipulation.

\section{Assessment of genetic stability after cryopreservation}

Cryopreservation has become an important tool for long-term storage of germplasm through the use of experimental materials that possess unique attributes to minimize space and maintenance requirements without causing genetic alterations (Sakai, 1997). However, inadequate cryopreservation techniques can lead to regenerated shoots tips developing calluses and result in genetic changes (Harding and Staines, 2001). Charoensub et al. (2004) mentioned that callus formation might increase the frequency of genetic changes occurring. However, optimized conditions for cryopreservation can provide higher rates of regrowth after thawing and result in few or no genetic changes of regenerated plants (Sakai and Engelmann, 2007). However, the possibility of genetic changes in cryopreserved plants has been a great concern for researchers. Many scientists have focused their efforts towards preventing genetic changes in cryopreserved and regenerated plant tissues (Fukai and Oe, 1990; Dixit-Sharama et al., 2005; Urbanova et al., 2006; Skyba et al., 2010; Vasanth and Vivier, 2011). However, the studies mentioned here showed no or small differences between cryopreserved and non-cryopreserved samples under optimized conditions. Morphological studies have also reported no significant changes (Hirai and Sakai, 2001). Using a biochemical approach, the

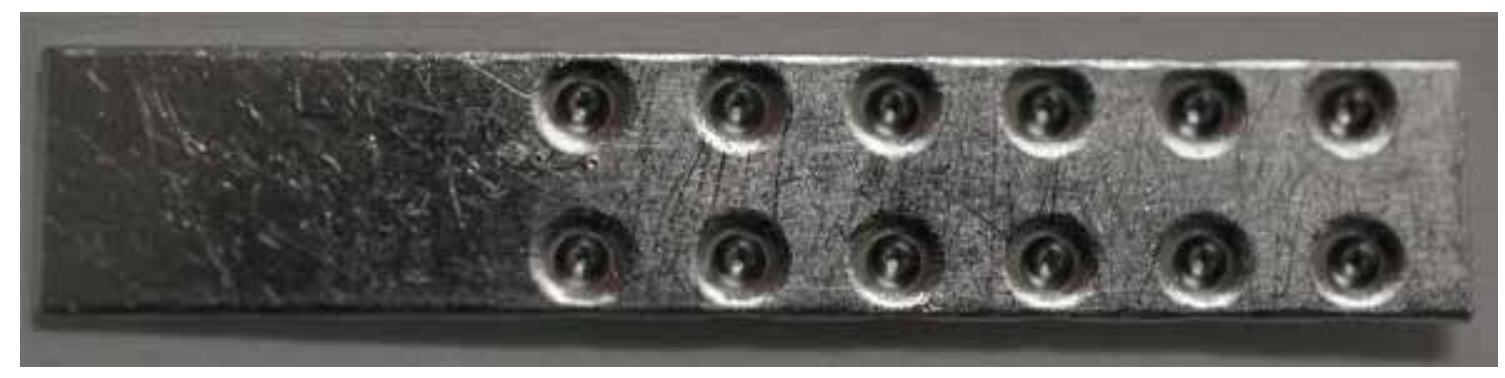

Fig.3. Aluminum cryo-plate.

Size: $7 \mathrm{~mm} \times 37 \mathrm{~mm} \times 0.5 \mathrm{~mm}$ with ten wells (diameter $1.5 \mathrm{~mm}$, depth $0.75 \mathrm{~mm}$ ). 
secondary metabolite content of medicinal plants cryopreserved has been analyzed after cryopreservation but found to be the same as that of controls (Yoshimatsu et al., 1996).

The genetic stability of recovered plants after long-term storage was assessed for 26 months using wasabi shoot tips that had been cryopreserved by vitrification for 10 years at $-150^{\circ} \mathrm{C}$ (deep freezer), 2 $\mathrm{h}$ at $-196^{\circ} \mathrm{C}(\mathrm{LN})$, a treated control with no cooling and a non-treated control with no cooling (Matsumoto et al., 2013). These samples were warmed and regenerated. The average recovery rates of samples were more than $90 \%$. The genetic stability of each of the regenerated wasabi plants was assessed using morphological, biochemical and molecular analyses. Initially, glucose, fructose and glutamic acid concentrations differed slightly among the samples; however, those differences disappeared after 8 months. No significant differences in morphological, biochemical and molecular analysis using RAPDPCR (five primers) were observed. Thus, cryopreserved and regenerated wasabi plants might not incur noticeable genetic changes during 10 years of cryopreservation storage.

Recently, methylation-sensitive amplified polymorphism (MSAP), which is a powerful technique for studying genome methylation status (Peredo et al., 2008; Nina et al., 2010; Rey et al., 2013), has been applied to evaluate the levels and patterns of cytosine methylation in plants. No genetic changes were detected using RAPD and AFLP to examine recovered cold-stored or cryopreserved hops (Humulus lupulus L.) plants, although methylation changes were detected by MSAP (Peredo et al., 2008). This technique was successfully used to identify epigenetic variation following cold storage and cryopreservation (Peredo et al., 2008, Maki et al., 2015). Methylation changes might have accumulated in long-term cultivated shoots.

\section{References}

Castillo NRF, Bassil NV, Wada S and Reed BM (2010) Genetic stability of cryopreserved shoot tips of Rubus germplasm. In Vitro Cell. Dev. Biol. Plant 46: 246-256.

Charoensub R, Hirai D and Sakai A (2004) Cryopreservation of in vitro-grown shoot tips of cassava by encapsulation-vitrification method. CryoLett. 25: 51-58.

Dixit-Sharma S, Ahuja-Ghosh S, Mandel BB and Srivastava PS (2005) Metabolic stability of plants regenerated from cryopreserved shoot tips of Dioscorea deltoidea - An endangered medicinal plant. Sci. Hort. 105: 513-517.

Dhungana SA, Kunitake H, Niino T, Yamamoto S, Fukui K and Matsumoto T (2015) Cryopreservation of blueberry (Vaccinium L.) shoot tips by D cryo-plate method. Hort. Res. (Japan) 14 (suppl. 2): 363.

Dereuddre J, Blandis S and Hassen N (1991a) Resistance of alginate-coated somatic embryos of carrot (Daucus carota L.) to desiccation and freezing in liquid nitrogen: 1. Effects of preculture, CryoLett. 12: 125-134.

Engelmann F (2004) Plant Cryopreservation: Progress and Prospects. In Vitro Cell. \& Devel. Biol. Plant 40(5): 427-433.

Engelmann F, Gonzalez MTY, Wu Y and Escobar R (2008) Development of Encapsulation Dehydration, In: Plant Cryopreservation: A Practical Guide. (Barbara MR, ed). pp.5975. Springer New York.

Febre J, and Dereuddre J (1990) Encapsulation-dehydration: A new approach to cryopreservation of solanum shoot-tips, CryoLett., 11: 413-426.

Fukai S and Oe M (1990) Morphological observations of chriysanthemum shoot tips cultured after cryopreservation and freezing. J Japan. Soc. Hort. Sci. 59: 383-387.

Harding K and Staines H (2001) Biometric analysis of phenotypic characters of tomato shoot tips recovered from tissue culture. dimethyle sulphoxide treatment and cryopreservation. CryoLett. 22: $255-262$.

Hirai D, Shirai K, Shirai S and Sakai A (1998) Cryopreservation of in vitro-grown meristems of strawberry (Fragaria $\times$ ananassa Duch.) by encapsulation-vitrification. Euphytica 101: 109-115.

Hirai D and Sakai A (2001) Recovery growth of plants cryopreservation by encapsulation-vitrification, Bul. Hokkaido Pref. Agri. Exp. Sta. 80: 55-64.

Kartha KK, Leung NL and Mroginski LA (1982) In vitro growth responses and plant regeneration from cryopreserved meristems of cassava (Manihot esculenta Crantz). Zeitschrift für Pflanzenphysiologie 107, 133-140.

Kaviani B (2011) Conservation of plant genetic resources by cryopreservation. Australian J. Crop Sci. 5: 778-800.

Keller ERJ and Dreiling M (2002) Potato cryopreservation in Germany-using the droplet method for the establishment of a new large collection. In: Proc. Int. Hort. Con. Toronto, Canada.

Kim HH, Lee YG, Park SU, Lee SC, Baek HJ, Cho EG and Engelmann F (2009) Development of alternative loading solutions in droplet-vitrification procedures. CryoLett. 30: 291-299.

Kumu Y, Harada T and Yakuwa T (1983) Development of a whole plant from a shoot tip of asparagus officinalis L. frozen down to $-196{ }^{\circ} \mathrm{C}$. Journal of the Faculty of Agriculture, Hokkaido University 61: 285-394.

Leunufna S and Keller ERJ (2003) Investigating a new cryopreservation protocol for yam (Discorea spp.). Plant Cell Reports, 21: 1159-1166.

Maki S, Hirai Y, Niino T and Matsumoto T (2015) Assessment of molecular genetic stability between long-term cryopreserved and tissue cultured wasabi (Wasabia japonica) plants, CryoLett. 36:318-324.

Martin C and Gonzalez-Benito ME (2005) Survival and genetic 
stability of Dendranthema grandiflora Tzvelev shoot apices after cryopreservation by vitrification and encapsulationdehydration, Cryobiol. 51: 281-289.

Matsumoto T, Sakai A and Yamada K (1994) Cryopreservation of in vitro-grown apical meristems of wasabi (Wasabia japonica) by vitrification and subsequent high plant regeneration. Plant Cell Rep. 13: 442-446.

Matsumoto T, Sakai A, Takahashi C and Yamada K (1995a) Cryopreservation of in vitro-grown meristems of wasabi (Wasabia japonica) by encapsulation-vitrification method. CryoLett. 16: 189-196.

Matsumoto T, Sakai A, and Yamada K (1995b) Cryopreservation of in vitro-grown apical meristems of lily (Lilium japonicum) by vitrification, Plant Cell Tiss. Org. Cul. 41: 231-241.

Matsumoto T, Takahashi C, Sakai A and Nako Y (1998) Cryopreservation of in vitro-grown apical meristems of hybrid statice by three different procedures. Sci. Hort. 76: 105-114.

Matsumoto T, T. Akihiro, Maki S, Mochida K, Kitagawa M, Tanaka D, Yamamoto S and Niino T (2013) Genetic stability assessment of Wasabi plants regenerated from long-term cryopreserved shoot tips using morphological, biochemical and molecular analysis, CryoLett. 34: 128-136.

Matsumoto T. and T. Niino (2014) The development of plant vitrification solution 2 and recent PVS2-based vitrification protocols. In: Reed, B.M. (ed.) Proceedings of the Second International Symposium on Plant Cryopreservation. Acta Hort. 1039: 21-28.

Matsumoto T, Yamamoto S, Fukui K and Niino T (2014a) Cryopreservation of blueberry dormant shoot tips using V cryoplate method. 2014 Annu. confe. Ameri. soc. horti. sci.: S337.

Matsumoto T, Yoshimatsu K, Kawahara N, Yamamoto S and Niino T (2014b) Development of in vitro propagation by node culture and cryopreservation by V Cryo-plate method for Perilla frutescens, Adv. Hort. Sci., 28: 79-83.

Matsumoto T, Yamamoto S, Fukui K, Rafique T, Engelmann F and Niino T (2015) Cryopreservation of persimmon shoot tips from dormant buds using the D cryo-plate technique, The Hort. J. 84: 106-110.

Niina R, Castillo F, Bassil NV, Wada S and Reed BM (2010) Genetic stability of cryopreserved shoot tips of Rubus germplasm, In Vitro Cell. Dev. Biol. Plant 46: 246-256.

Niino T (2006) Developments in plant genetic resources cryopreservation technologies. In proceedings of the APEC workshop on effective gene bank management in APEC member economies. Suwon, Korea, pp. 197-217.

Niino T, Yamamoto s, Fukui K, Martínez CRC, Arizaga MV, Matsumoto T and Engelmann F (2013) Dehydration improves cryopreservation of mat rush (Juncus decipiens Nakai) basal stem buds on cryo-plate, CryoLett. 34: 549-560.

Niino T, Wunna, Watanabe K, Nohara N, Rafique T, Yamamoto S, Fukui K, Arizaga MV, Martinez CRC, Matsumoto T and Engelmann F (2014) Cryopreservation of mat rush lateral buds by air dehydration using aluminum cryo-plate, Plant Biot. 31: 281-287.

Panis B (1995) Cryopreservation of Banana (Musa spp.) Germplasm. Doctoral Paper (No. 272), Katholieke Universiteit Leuven, Belgium.

Pennycooke JC and Towill LE (2001) Medium alterations improve regrowth of sweet potato (Ipomoea batatas (L.) Lam.) shoot tips cryopreserved by vitrification and encapsulationdehydration. CryoLett. 22: 381-389.

Peredo EL, Arroyo-Garcia R, Reed BM and Revilla MA (2008) Genetic and epigenetic stability of cryopreserved and coldstored hops (Humulus lupulus L.) Cryobiol. 57: 234-241.

Phunchindawan M, Hirata K, Miyamoto K and Sakai A (1997) Cryopreservation of encapsulated shoot primordia induced in horseradish (Armoracia rusticana) hairy root cultures. Plant Cell Rep. 16: 469-473.

Reed BM (2008) Cryopreservation-Practical considerations, In: Plant Cryopreservation: A Practical Guide (Reed BM, ed), Springer, New York, pp.3-13.

Rey NA, Papacchioli V, Tavazza R and Pagnotta MA (2013) Gauging the genetic changes occurring across globe artichoke micropropagation towards an appropriate variety registration and nursery production. Sci. Hort. 156: 121-126.

Rafique T, Yamamoto S, Fukui K, Mahmood Z and Niino T (2015) Cryopreservation of sugarcane using the V cryo-plate technique. CryoLett. 36: 51-59.

Sakai A and Yoshida S (1967) Survival of plant tissue at superlow temperature VI. Effects of cooling and rewarming rates on survival. Plant Physiol. 42: 1695-1701.

Sakai A, Kobayashi S and Oiyama I (1990) Cryopreservation of nucellar cells of navel orange (Citrus sinensis Osb. var. brasiliensis Tanaka) by vitrification. Plant Cell Rep. 9: 30-33.

Sakai A (1995) Cryopreservation of germplasm of woody plants, in Biotechnology in Agriculture and Forestry 32, Cryopreservation of Plant Germplasm I, (Bajaj YPS, ed), Springer-Verlag, Berlin, Heidelberg, pp. 53-69.

Sakai A (1997) Conservation of Plant Genetic Resources In Vitro, (eds) Razdan MK and Cocking EC, Science Publishers, New Hampshire, pp.53-66.

Sakai A and Engelmann F (2007) Vitrification, encapsulationvitrification and droplet-vitrification: A review. CryoLett. 28: 151-172.

Sakai A (2008) Development of PVS-based vitrification and encapsulation-vitrification protocols, In: Plant cryopreservation A practical guide (Reed MB, ed), Springer, New York, pp.33-57. 
Please cite this article as Matsumoto, Reviews in Agricultural Science, 5:13-20, 2017 Doi: $10.7831 /$ ras 5.13

Salma M, Fki L, Engelmann-Sylvestre I, Niino T and Engelmann F (2014) Comparison of droplet-vitrification and D-cryoplate for cryopreservation of date palm (Phoenix dactylifera L.) polyembryonic masses, Sci. Hort. 179: 91-97.

Schafer-Menuher A, Schumacher HM and Mix-Wagner (1997) Cryopreservation of potato cultivars-design of a method for routine application in genebanks. In: Proc. III int. Sym. In vitro cul. hort. Breed.

Sekizawa K, Yamamoto S, Rafique T, Fukui K and Niino T (2011) Cryopreservation of in vitro-grown shoot tips of carnation (Dianthus caryophyllus L.) by vitrification method using aluminium cryo-plates, Plant Biot. 28: 401-405.

Skyba M, Urbanova M, Toteva VK, Kosuth J, Harding K and Ellarova E (2010) Physiological, biochemical and molecular characteristics of cryopreserved Hypericum Perforatum L. shoot tips. CryoLett. 31: 249-260.

Urbanova M, Kosuth J and Cellarova E (2006) Genetic and biochemical analysis of Hypericum perforatum L. plants regenerated after cryopreservation. Plant Cell Rep. 25: 140-147.

Vasanth K and Vivier MA (2011) Improved cryopreservation procedure for long term storage of synchronised culture of grapevine, Biologia Plantarum 55: 365-369.

Withers LA (1980) The cryopreservation of higher plant tissue and cell cultures - an overview with some current observations and future thoughts. CryoLett. 1: 239-250.

Yamamoto S, Rafique T, Priyantha WS, Fukui K, Matsumoto $\mathrm{T}$ and Niino T (2011) Development of a cryopreservation procedure using aluminium cryo-plates, CryoLett. 32: 256-265.

Yamamoto S, Rafique T, Fukui K, Sekizawa K and Niino T (2012a) V-Cryo-plate procedure as an effective protocol for cryobanks: Case study of mint cryopreservation, CryoLett. 33: 12-23.

Yamamoto S, Fukui K, Rafique T, Khan NI, Martinez CRC, Sekizawa K, Matsumoto T and Niino T (2012b) Cryopreservation of in vitro-grown shoot tips of strawberry by the vitrification method using aluminium cryo-plates, Plant Gen. Res.: Charac. and Uti. 10: 14-19.

Yamamoto S, Rafique T, Sekizawa K, Koyama A, Ichihshi T and Niino T (2012c) Development of an effective cryopreservation protocol using alminium cryo-plates for in vitro-grown shoot tips of mulberries (Morus spp.) originated from the tropics and subtropics. Sanshi-Konchu Biotec, 81: 57-62. (in Japanese)

Yamamoto S, Rafique, Arizaga MV, Fukui K, Gutierrez EJC, Martinez CRC, Watanabe K and Niino T (2015) The aluminum cryo-plate increases efficiency of cryopreservation protocols for potato shoot tips, Amer. J. Potato Res. 92: 250-257.

Yoshimatsu K, Yamaguchi H \& Shimomura K (1996) Traits of Panax ginseng hairy roots after cold storage and cryopreservation. Plant Cell Reports 15: 555-560. 